medRxiv preprint doi: https://doi.org/10.1101/2020.08.05.20168948; this version posted August 6, 2020. The copyright holder for this preprint (which was not certified by peer review) is the author/funder, who has granted medRxiv a license to display the preprint in perpetuity.

All rights reserved. No reuse allowed without permission.

\title{
Development of mass spectrometry-based targeted assay for direct detection of novel SARS-CoV-2 coronavirus from clinical specimens
}

Santosh Renuse ${ }^{1,2, *}$, Patrick M. Vanderboom ${ }^{1, *}$, Anthony D. Maus ${ }^{1, *}$, Jennifer V. Kemp ${ }^{1}$, Kari M. Gurtner $^{1}$, Anil K. Madugundu ${ }^{1,3,4,5}$, Sandip Chavan ${ }^{1}$, Jane A. Peterson ${ }^{6}$, Benjamin J. Madden ${ }^{6}$, Kiran K. Mangalaparthi ${ }^{1,7}$, Dong-Gi Mun ${ }^{1}$, Smrita Singh ${ }^{1,3,4,5}$, Benjamin R. Kipp ${ }^{8}$, Surendra Dasari ${ }^{9}$, Ravinder J. Singh ${ }^{1, \S}$, Stefan K. Grebe ${ }^{1,10, \S}$ and Akhilesh Pandey ${ }^{1,2,5, \S}$

${ }^{1}$ Department of Laboratory Medicine and Pathology, Division of Clinical Biochemistry and Immunology, Mayo Clinic, Rochester, MN 55905, USA

${ }^{2}$ Center for Individualized Medicine, Mayo Clinic, Rochester, MN 55905, USA

${ }^{3}$ Institute of Bioinformatics, International Technology Park, Bangalore, 560066, Karnataka, India

${ }^{4}$ Manipal Academy of Higher Education, Manipal, 576104, Karnataka, India

${ }^{5}$ Center for Molecular Medicine, National Institute of Mental Health and Neurosciences, Hosur Road, Bangalore, 560029, Karnataka, India

${ }^{6}$ Proteomics Core, Medical Genome Facility, Mayo Clinic, Rochester, MN 55905, USA

${ }^{7}$ Amrita School of Biotechnology, Amrita Vishwa Vidyapeetham, Kollam, 690525, Kerala, India

${ }^{8}$ Department of Laboratory Medicine and Pathology, Division of Laboratory Genetics and Genomics, Mayo Clinic, Rochester, MN 55905, USA

${ }^{9}$ Division of Biomedical Statistics and Informatics, Department of Health Sciences Research, Mayo Clinic, Rochester, MN 55905, USA

${ }^{10}$ Department of Medicine, Division of Endocrinology, Mayo Clinic, Rochester, MN 55902, USA

*Shared first authors

${ }^{\S}$ Corresponding authors

\#Correspondence should be addressed to Akhilesh Pandey (pandey.akhilesh@ mayo.edu).

Akhilesh Pandey, M.D., Ph.D.

Professor

Department of Laboratory Medicine and Pathology, Mayo Clinic

200 First ST SW, Rochester, MN 55905

Phone: 507-293-9564

Email: pandey.akhilesh@mayo.edu 
medRxiv preprint doi: https://doi.org/10.1101/2020.08.05.20168948; this version posted August 6, 2020. The copyright holder for this preprint (which was not certified by peer review) is the author/funder, who has granted medRxiv a license to display the preprint in perpetuity.

All rights reserved. No reuse allowed without permission.

\begin{abstract}
The COVID-19 pandemic caused by severe acute respiratory syndrome-coronavirus 2 (SARSCoV-2) has overwhelmed health systems worldwide and highlighted limitations of diagnostic testing. Several types of diagnostics including RT-PCR-based assays, antigen detection by lateral flow assays and antibody-based assays have been developed and deployed in a short time. However, many of these assays are lacking in sensitivity and/or specificity. Here, we describe an immunoaffinity purification followed by high resolution mass spectrometry-based targeted assay capable of detecting viral antigen in nasopharyngeal swab samples of SARS-CoV-2 infected individuals. Based on our discovery experiments using purified virus, recombinant viral protein and nasopharyngeal swab samples from COVID-19 positive patients, nucleocapsid protein was selected as a target antigen. We then developed an automated antibody capture-based workflow coupled to targeted high-field asymmetric ion mobility spectrometry (FAIMS) - parallel reaction monitoring (PRM) assays on an Orbitrap Exploris 480 mass spectrometer. An ensemble machine learning-based model for determining COVID-19 positive samples was created using fragment ion intensities in the PRM data. This resulted in $97.8 \%$ sensitivity and $100 \%$ specificity with RTPCR-based molecular testing as the gold standard. Our results demonstrate that direct detection of infectious agents from clinical samples by mass spectrometry-based assays have potential to be deployed as diagnostic assays in clinical laboratories.
\end{abstract}




\section{INTRODUCTION}

Coronaviruses are RNA viruses and include common human coronaviruses, severe acute respiratory syndrome-CoV (SARS-CoV), Middle East respiratory syndrome-CoV (MERS-CoV) and SARS-CoV-2 (1). Although the large majority of common cold infections caused by coronaviruses do not have any significant clinical sequelae, the more recently identified coronaviruses have caused major public health outbreaks $(2,3)$. SARS-CoV-2 is the cause of the current COVID-19 pandemic (4, 5). Patients with COVID-19 present with upper respiratory infections that can result in a number of complications particularly in patients of advanced age or with co-morbidities. Recent reports show that in many severely ill patients it progresses to a multi-system disorder involving blood vessels (abnormal blood clotting), heart (acute cardiac injury, myocarditis and cardiac arrhythmias), kidneys (acute renal injury), liver, gut and brain (6$15)$.

Accurate and timely laboratory diagnosis of COVID-19 is one of the most pivotal requirements for optimal disease management and contact tracing. Historically, cell culture was the mainstay of viral antigen detection, and it still remains necessary to a minor degree, because it is the only technique capable of providing a viable isolate that can be used for further characterization of the virus. Cell culture for virus isolation also remains a useful method for growing and studying viruses in research settings especially in the characterization of novel pathogenic viruses like SARS-CoV-2 although this requires more advanced containment facilities such as biosafety level 3 (BSL-3).

The vast majority of current laboratory testing for COVID-19 is based either on detection of viral antigens, nucleic acids or on detection of virus-specific antibodies in the sera of patients. Viral antigen detection is generally based on immunoassays while viral nucleic acid detection is performed by real time quantitative RT-PCR, droplet digital PCR (ddPCR) or, less commonly, by techniques such as isothermal amplification (16). Immunoassays offer moderate to good detection sensitivity and relative rapid analytical turnaround times, but some viruses such as enteroviruses and rhinoviruses have extensive antigenic heterogeneity, which makes them less amenable to antigen detection methods. Of the molecular methods, RT-PCR and dd-PCR typically have superior detection sensitivity compared to immunoassays and less problems with viruses that show antigenic shifts, while similar turnaround times to immunoassays. Detection of virus-specific antibodies allows for diagnosis of recent symptomatic or even asymptomatic infections. IgM antibodies are the first antibody isotype that develop rapidly within days after infection, while IgG levels take a week or longer to rise. Overall, the biggest advantage of nucleic acid-based assays is that a new assay for a previously unknown virus can generally be developed and validated in a matter of a days or a few weeks after the virus is first cultured, whereas development time lines for immunoassays are substantially longer $(17,18)$. However, the increased demand for PCR testing worldwide has resulted in test shortages and the acute need for more available accurate diagnostic tests.

Detection of viral material using liquid chromatography-tandem mass spectrometry (LCMS/MS) might also have sufficient sensitivity for viral antigen detection. Previous studies have suggested that detection of viral proteins in body fluids could be a rapid diagnostic method for severe acute respiratory syndrome (SARS) (19-21). Moreover, in the nearly two decades since 
the initial SARS outbreak, tremendous improvements have occurred in liquid chromatography as well as mass spectrometry and their applications in both research and clinical laboratories. The current generation of LC-MS-based approaches can be used for direct identification of viral proteins at relatively low concentrations and might therefore be suitable for clinical diagnostic applications. Nucleocapsid protein from SARS patients was abundant enough to be detected in clinical samples using an ELISA approach (20). Despite this, there are few, if any, studies which have focused on the detection of the viral proteins in biological samples by mass spectrometry. Targeted proteomic approaches utilizing multiple reaction monitoring or parallel reaction monitoring (MRM/PRM) are highly sensitive, allow robust detection and possess the analytical speed for clinical testing. In a pandemic situation, these approaches could supplement and complement nucleic acid based viral antigen testing. Here, we describe the development and evaluation of a mass spectrometry-based targeted assay for sensitive and accurate detection of viral antigenic peptides from nasopharyngeal swab samples of COVID-19 patients with high sensitivity and specificity.

\section{RESULTS AND DISCUSSION}

We first sought to analyze the SARS-CoV-2 viral proteome by analyzing inactivated SARS$\mathrm{CoV}-2$ virus and recombinant viral proteins to determine which proteins and peptides are detectable. The next step was to select the most promising peptides based on spectral abundance and response intensity and to create targeted PRM methods to characterize their performance. Finally, we developed targeted assays deploying automated antibody capture-based workflow, followed by a rapid separation low-flow LC method and a PRM MS method incorporating ion mobility for selected viral peptides. In all, we tested 363 nasopharyngeal residual swab samples from patients with matched clinical molecular test results

\section{SARS-CoV-2 proteome}

An overview of the genome organization of SARS-CoV-2 is presented in Figure 1A. This virus is most closely related to SARS-CoV and to MERS. The common human coronaviruses (OC43, HKU1, NL63 and L229E) are less related to SARS-CoV-2 than to each other. A sequence alignment of nucleocapsid protein in these coronaviruses is presented in Figure S1. A schematic of domain and functional organization of two of the major structural proteins of SARS-CoV-2, along with the location of the peptides identified in our studies is shown in Figure 1B.

\section{Nucleocapsid protein as a target viral antigen for assay development}

To characterize the SARS-CoV-2 proteome, we analyzed purified gamma-irradiated SARSCoV-2 virus samples (USA-WA1/2020 isolate) cultured in African green monkey (Chlorocebus aethiops) kidney cells (Vero E6). The inactivated virus samples were digested with trypsin and analyzed on a high resolution Orbitrap Eclipse mass spectrometer interfaced with an RSLCnano system using a $3 \mathrm{hr}$ gradient. Searches against a database that included proteins from African green monkey, humans and SARS-CoV-2 plus other coronaviruses (SARS-CoV, MERS and common human coronaviruses) identified 950 proteins from monkey, 100 proteins from human (likely because of lack of a complete protein database for monkey) and 5 proteins (50 peptides) 
from SARS-CoV-2 including nucleocapsid (23 peptides), spike glycoprotein (22 peptides), membrane protein ( 2 peptides), orfla (1 peptide) and orf9b (2 peptides) (Table S1).

SARS-CoV-2 nucleocapsid is highly expressed during infection (22) and a potential target for viral detection by mass spectrometry. The nucleocapsid protein forms a supercoiled helix structure and helps package the single stranded viral RNA genome with at least 1,000 nucleocapsid molecules per virion $(23,24)$. Since, cells infected with SARS-CoV-2 often contain several virions, it is therefore possible to detect even relatively low viral loads in patient samples with modern LC-MS/MS instrumentation. Indeed, we consistently detected nucleocapsid-derived peptides as the most abundant peptides in our studies of the inactivated virus Trypsin digestion and analysis by untargeted LC-MS/MS of recombinant nucleocapsid protein was undertaken to identify candidate peptides for targeted detection by LC-MS/MS assays. This analysis identified 32 peptides, most of which were unique to SARS-CoV-2 (13 were indistinguishable from SARS$\mathrm{CoV}$ ) (Figure S1). Peptides identified from SARS-CoV-2 recombinant nucleocapsid protein are summarized in Figure 1C and Table S1. To test if the peptides identified from these overexpression systems would also be identified from clinical samples, we performed LCMS/MS-based deep proteomic profiling of pooled nasopharyngeal samples that had been confirmed by molecular test as SARS-CoV-2 positive. Database searches against human and SARS-CoV-2, SARS-CoV, MERS and other common human coronavirus proteins resulted in identification of 5,269 human proteins (50,540 peptides) and 5 proteins (55 peptides) from SARS-CoV-2 which included nucleocapsid protein (36 peptides), spike glycoprotein (3 peptides), membrane protein (1 peptide), orf9b (3 peptides) and orf8 ( 2 peptides), which was highly similar to the profiles previously obtained. Of the peptides that could uniquely identify SARS-CoV-2, four were chosen for targeted assay development for optimal detection (25) (Figure 2A-D) - all of them were unique to SARS-CoV-2 as shown by the sequence alignment with SARS-CoV, MERS and other common human coronaviruses (Figure 2E).

\section{Optimization of pre-analytical variables}

Based on our discovery experiments, we decided upon nucleocapsid protein as our target antigen for assay development. We optimized several pre-analytical parameters including protein extraction, various antibodies for capture of nucleocapsid protein and the use of ion mobility.

\section{A. Protein extraction optimization}

To maximize protein yield from nasopharyngeal swab samples, we tested several protein extraction methods including methanol precipitation, 2\% SDS, 0.002\% Z316 zwitterionic detergent and RIPA buffer. The processed samples were immunopurified and MS/MS fragment intensities for AYNVTQAFGR and QQTVTLLPAADLDDFSK peptides were compared. From these experiments, $0.002 \% \mathrm{Z} 316$ was selected for protein extraction and subsequent capture using antibody.

\section{B. Direct digest and immunopurification}

Next, we tested if we could detect the nucleocapsid protein directly after proteolytic digest or if enrichment using an anti-nucleocapsid antibody prior to digestion was required for detection. For 
this comparison, a monoclonal antibody (Sino Biological, Wayne PA, Cat\# 40143-R001) was biotinylated and immobilized to streptavidin mass spectrometry immunoassay (MSIA) tips for capture using an automated liquid handler. In all, 89 patient samples were analyzed with each method ( 69 positive and 20 negative as tested by RT-PCR). To determine if antibody enrichment resulted in an increase in sensitivity, a cutoff was established at 3 standard deviations above the average peak height observed for AYNVTQAFGR and QQTVTLLPAADLDDFSK in the 20 RT-PCR negative samples. Peptide signals above the cutoff threshold in RT-PCR positive samples were then counted. Antibody enrichment resulted in 14 and 24 additional positive samples which were above the cutoff for AYNVTQAFGR and QQTVTLLPAADLDDFSK, respectively. The additional samples above the cutoff in antibody enriched samples had higher $\mathrm{Ct}$ values (i.e. lower viral loads) as compared to samples above the cutoff for both the methods, indicating that immunoaffinity enrichment results in a greater sensitivity relative to direct digest (Table S2).

\section{Antibody enrichment optimization}

To improve the efficiency of nucleocapsid capture, 17 different antibodies against the nucleocapsid protein were evaluated (Table S3). Four antibodies which displayed the best performance characteristics were compared side by side using pooled patient samples with high, medium or low viral loads (based on $\mathrm{Ct}$ values from real time quantitative RT-PCR-based molecular testing). This comparison identified two monoclonal antibodies with suitable performance from which we selected one for further development of the assay.

\section{Improved sensitivity with ion mobility}

In discovery LC-MS/MS analysis of eluates after nucleocapsid enrichment from nasopharyngeal samples, we detected $>2,000$ peptides. This poses unique challenges especially if short chromatographic separation is desired for targeted detection owing to interference from the highly complex matrix. Orthogonal gas phase separation such as ion mobility for separation of charged ions based on their size could potentially provide additional separation that might be beneficial. A front-end high-field asymmetric waveform ion mobility spectrometry (FAIMS) source typically filters ions entering into the ion transfer capillary by reducing background chemical noise resulting in increased sensitivity and robustness $(26,27)$ To determine if FAIMS could increase specificity for the viral peptides, we optimized compensation voltages for the peptides of interest from nucleocapsid protein. Those that resulted in the highest signal intensities were chosen to build the targeted method (Table S4). We analyzed nasopharyngeal swab samples with and without FAIMS and observed significantly improved signal-to-noise $(\mathrm{S} / \mathrm{N})$ ratio with FAIMS. Figure S2A shows the PRM signal of AYNVTQAFGR peptide from a representative nasopharyngeal swab sample (relatively high viral load; Ct value of 20) where the S/N with FAIMS was 965 as compared to 67 without FAIMS. Figure S2B shows the PRM signal for AYNVTQAFGR peptide in another representative nasopharyngeal swab sample with a low viral load (Ct value of 30) that could not be detected without FAIMS. Based on these data, we incorporated FAIMS into our assay workflow.

\section{High-throughput assays for detection of SARS-CoV-2}


After optimization of protein extraction, capture and LC-MS/MS acquisition parameters, we selected two peptides for the final targeted assay. To maintain optimal performance, the sample preparation and chromatography conditions were further refined. The sample preparation workflow was automated using Versette liquid handler which minimized overall time and experimental variation during sample processing. The throughput and robustness of the sample analysis was achieved by coupling Evosep One with Exploris 480 mass spectrometer, allowing analysis of 100 samples per day without sacrificing sensitivity.

Synthetic isotopically labeled heavy peptides were used for optimization of LC-MS/MS parameters including collision energy, retention time and relative intensity of fragment ions. Table 1 shows details of peptides including sequence, precursor $\mathrm{m} / \mathrm{z}$, charge, retention time and FAIMS compensation voltages. This optimized assay was used to analyze 363 residual nasopharyngeal swab samples previously tested by quantitative real time RT-PCR. Figure 3 shows a schematic of optimized workflow for the diagnosis of SARS-CoV-2 using FAIMS-PRM targeted mass spectrometry.

We analyzed 187 nasopharyngeal swab samples (116 positive and 71 negative) using the optimized FAIMS-PRM workflow and used supervised machine learning to select the optimal fragments and determine their weights for maximizing the performance of the targeted mass spectrometry assay. Using this as a training dataset, we employed an ensemble-based machine learning approach encoded in Super Learner as described previously (28). This method was configured to use a generalized linear model via penalized maximum likelihood (glmNET), generalized linear model (GLM) and random forest (RF) model; all configured to use binomial distribution. A 10-fold cross-validation with a goal to maximize the AUC and to prevent overfitting was instituted during the learning process. An optimal weighted average of the trained models (i.e glmNET, GLM and RF) was computed and considered as a final composite model to evaluate performance on an independent validation dataset. This ensemble method incorporated a total of 17 fragments, resulting in an AUC of 0.9956 on the training set. Based on the probability distribution of negative and positive samples in the training set, we chose a probability of $\geq 0.6$ as threshold for calling a positive sample (Figure 4A and 4B). We applied this composite model to an independent validation dataset of 176 samples (88 positive and 88 negative samples) using the exact same optimized FAIMS-PRM workflow. This resulted in achieving a sensitivity of $97.8 \%$ and specificity of $100 \%$ with an AUC $=1.0$. These results show that our assay for the detection of SARS-CoV-2 antigen performed with a very high sensitivity and specificity, especially compared to other reported rapid antigen lateral flow assays (29).

\section{Assay performance as compared to RT-PCR tests}

Although RT-PCR remains the well-established gold standard for viral pathogen detection, the FAIMS-PRM workflow displays very high sensitivity and specificity. To ensure that samples used for training and validation of the model reflect the distribution observed in a large population, we mimicked the distribution of Ct values for 11,575 SARS-CoV-2 positive patients tested at Mayo Clinic (Figure 4C) in the training and test set samples (Figure 4D). Ct values obtained from the large population approximate a normal distribution (mean $=26.5, \mathrm{IQR}=21.1$ 31.3) and agree well with the training and validation samples (mean $=26.5$, IQR $=21.8-31.4$ ). While naïve, uncalibrated $\mathrm{Ct}$ values are not themselves quantitative they can serve as an estimate 
of relative target abundance. Peptide peaks heights derived from mass spectrometry analysis also provide semi quantitative information. To determine the feasibility of using peak heights as an estimate of viral abundance $\mathrm{Ct}$ values were correlated to peak heights using the training and validation data sets (Figure 4E and 4F). Indeed, both peptides display good correlation with $\mathrm{Ct}$ values (QQTVTLLPAADLDDFSK $r^{2}=0.73$, AYNVTQAFGR $r^{2}=0.73$ ) indicating that viral peptide peak height may additionally serve as an estimate of viral abundance.

\section{Conclusions}

In this study, we report development of a mass spectrometry-based targeted assay that permits direct detection of viral antigens from clinical specimens. A key advantage of this targeted method is the high specificity and comparable sensitivity to the gold standard RT-PCR method for the diagnosis of SARS-CoV-2. Definitive identification by this method can also serve as a reference method for other antigen testing assays such lateral flow assays, many of which lack sensitivity. In addition, the method can be applied to other sample types (e.g. urine, saliva) and can be adapted for detection of novel variants of SARS-CoV-2 as they appear. Finally, our method with rapid chromatographic separation followed by highly sensitive mass spectrometry detection provides a throughput of 100 samples per day and can be easily deployed at routine clinical laboratories with mass spectrometry instrumentation.

\section{Acknowledgments}

The following reagent was deposited by the Centers for Disease Control and Prevention and obtained through BEI Resources, NIAID, NIH: SARS-Related Coronavirus 2, Isolate USAWA1/2020, Gamma-Irradiated, NR-52287. This study was supported by 'DBT/Wellcome Trust India Alliance' Margdarshi Fellowship grant IA/M/15/1/502023 awarded to AP.

\section{Data Availability}

The mass spectrometry proteomics data have been deposited to the ProteomeXchange Consortium via the PRIDE partner repository with the dataset identifier PXD020644.

Reviewer account details:

Username: reviewer94766@ebi.ac.uk

Password: J8setKN6

\section{Conflict of interest statement}

All authors declared that there is no conflict of interests. 


\section{MATERIALS AND METHODS}

\section{COVID-19 specimen collection and handling}

All samples were collected after informed consent and approval by the institutional review board. All clinical samples were de-identified prior to analysis.

\section{Chemicals and reagents}

The following reagents were deposited by the Centers for Disease Control and Prevention and obtained through BEI Resources, NIAID, NIH: SARS-Related Coronavirus 2, Isolate USAWA1/2020, gamma-irradiated, NR-52287. Tris (2-carboxyethyl)phosphine hydrochloride (TCEP) and iodoacetamide were purchased from Sigma (St. Louis, MO, USA). Phosphate buffered saline (PBS) was purchased from Bio-Rad (Hercules, CA, USA). Trifluoroacetic acid (TFA) was purchased from Thermo Fisher Scientific (Waltham, MA, USA). Zwittergent Z3-16 was purchased from CalBiochem (EMD Millipore, Billerica, MA, USA). Dynabeads M-280 Streptavidin was purchased from Invitrogen (Carlsbad, CA, USA). Trypsin/Lys-C Mix and Rapid Digestion kit was purchased from Promega (Madison, WI, USA). Recombinant SARSCoV-2 nucleocapsid protein (97-077) was purchased from ProSci (Fort Collins, CO).

\section{Synthesis of isotopically labeled heavy peptide standards}

All SARS-CoV-2-derived peptides were synthesized using standard FMOC chemistry on a Liberty Blue (CEM Corp. Matthews, NC) peptide synthesizer with methods suggested by the manufacturer. Starting resin was either arginine (pbf) ${ }^{13} \mathrm{C}_{6},{ }^{15} \mathrm{~N}_{4}$ 2Cl-trt resin or lysine (boc) ${ }^{13} \mathrm{C}_{6}$ ${ }^{15} \mathrm{~N}_{2}$ 2Cl-trt resin (Cambridge Isotope Laboratories, Tewksbury, MA), depending on the sequence. A second stable isotope labeled amino acid was incorporated into the sequence using Fmoc-Leucine-OH ${ }^{13} \mathrm{C}_{6}{ }^{15} \mathrm{~N}$, Fmoc-Glycine-OH ${ }^{13} \mathrm{C}_{2}{ }^{15} \mathrm{~N}$, or Fmoc-Alanine-OH ${ }^{13} \mathrm{C}_{3}$ (IsoTec, Inc., Miamisburg, $\mathrm{OH}$ ) as dictated by the sequence. Peptides were cleaved using the CEM Razor cleavage module heated to $42^{\circ} \mathrm{C}$ for $40 \mathrm{~min}$. Cleavage cocktail was trifluoroacetic acid, water, triisopropyl silane and 3,6-Dioxa-1,8-octanedithiol (92.5/2.5/2.5/2.5 v/v/v/v). Peptides were precipitated in cold methyl-t-butyl ether, washed and dried for purification. Purification was achieved by reversed-phase HPLC using a Phenomenex Jupiter $\mathrm{C}_{18}$ column, 250 × $21.2 \mathrm{~mm}$, using a water/acetonitrile buffer system. Peptide purity and integrity were confirmed using an Agilent InfinityLab II LC/ MSD (Agilent Technologies, Santa Clara, CA) system.

\section{Processing of nasopharyngeal swab samples and in-solution trypsin digestion}

Nasopharyngeal swab samples were collected in PBS and digested directly in-solution. $100 \mu 1$ of sample was diluted three-fold with rapid digest buffer (Promega, Madison WI) and $1.5 \mu \mathrm{g}$ of trypsin was added. The samples were placed on a thermomixer (Thermo Scientific, Waltham, MA) at $70^{\circ} \mathrm{C}$ for $1 \mathrm{hr}$ with rotation at $1,150 \mathrm{rpm}$ for trypsin digestion. To terminate the digestion, the samples were acidified to $0.2 \%$ TFA. The samples were desalted using $\mathrm{C}_{18}$ solid phase extraction spin columns (Glygen, Columbia, MD), dried down and reconstituted in $20 \mu 1$ of $0.2 \%$ formic acid. Recombinant proteins and inactivated purified SARS-CoV-2 were digested using the method described above for the swab samples with the following modifications: protein 
content of the purified SARS-CoV-2 was estimated using a BCA assay (Pierce Waltham, MA) and trypsin was added to all samples at a 1:10 enzyme to substrate ratio. Following digestion, disulfide bonds were reduced and cysteines were alkylated simultaneously with the addition of 5 $\mathrm{mM}$ TCEP and $5 \mathrm{mM}$ IAA. Samples were incubated in dark for $30 \mathrm{~min}$ at room temperature prior to sample acidification and cleanup.

\section{Untargeted LC-MS/MS experiments}

LC-MS/MS analysis for untargeted discovery proteomics experiments was carried out using an Ultimate 3000 RSLCnano system (Thermo Scientific, San Jose, CA) connected to an Orbitrap Eclipse mass spectrometer (Thermo Scientific, San Jose, CA). The peptides were loaded onto a trap column (PepMap $\mathrm{C}_{18} 2 \mathrm{~cm} \times 100 \mu \mathrm{m}, 100 \AA$ ) at a flow rate of $20 \mu \mathrm{l} / \mathrm{min}$ using $0.1 \%$ formic acid and separated on an analytical column (EasySpray $50 \mathrm{~cm} \times 75 \mu \mathrm{m}, \mathrm{C}_{18} 1.9 \mu \mathrm{m}, 100 \AA$, Thermo Scientific, San Jose, CA) with a flow rate of $300 \mathrm{nl} / \mathrm{min}$ with a linear gradient of 5 to $40 \%$ solvent $\mathrm{B}(100 \% \mathrm{ACN}, 0.1 \%$ formic acid) over a 40 min gradient. Both precursor and fragment ions were acquired in the Orbitrap mass analyzer. Precursor ions were acquired in $\mathrm{m} / z$ range of 350-1700 with a resolution of 120,000 (at $\mathrm{m} / \mathrm{z}$ 200). Precursor fragmentation was carried out using higher-energy collisional dissociation (HCD) method using normalized collision energy (NCE) of 28. The fragment ions were acquired at a resolution of 30,000 (at $\mathrm{m} / \mathrm{z}$ 200). The scans were arranged in top-speed method with 3 seconds cycle time between MS and MS/MS. Ion transfer capillary voltage was maintained at $2.5 \mathrm{kV}$. For internal mass calibration, lock mass option was enabled with polysiloxane ion $(\mathrm{m} / \mathrm{z}, 445.120025)$ from ambient air.

\section{Anti-nucleocapsid antibody-based enrichment of nucleocapsid protein and in-solution trypsin digestion}

In order to improve the sensitivity of the detection, we evaluated a number of antibodies as shown in Table S3. Briefly, antibody was biotinylated using biotinylation kit (ThermoFisher Scientific, San Jose, CA) as per manufacturer's instructions. Biotinylated antibody (1 $\mu \mathrm{g})$ was coated on streptavidin MSIA tips (Catalog\#991STR11, ThermoFisher Scientific, San Jose, CA) in $0.1 \%$ BSA containing $1 \mathrm{X}$ PBS on the Versette automated liquid handler (ThermoFisher Scientific, San Jose, CA). Nasopharyngeal swab samples $(750 \mu 1)$ were mixed with zwitterion $\mathrm{Z} 316$ at final concentration of $0.002 \%$ in 96 well plate and were inactivated at $70^{\circ} \mathrm{C}$ for 30 minutes. Inactivated samples were subjected to enrichment using mass spectrometry immunoassay (MSIA)-based enrichment using biotinylated antibody, washed two times with 200 $\mu 1$ 1X PBS and eluted in $100 \mu \mathrm{l}$ of $50 \%$ ACN/0.002\% Z316 in $0.1 \%$ TFA. Sample eluent was mixed with $300 \mu$ of rapid trypsin digestion buffer (Promega Corporation, Madison, WI) and subjected to in-solution trypsin digestion (Gold Trypsin, Promega Corporation, Madison, WI) at $70^{\circ} \mathrm{C}$ for 1 hour on a shaker incubator. The digest was acidified using TFA to a final concentration of $1 \%$ TFA. The acidified digests were spiked-in with synthetic isotope labelled heavy peptides and the samples were loaded on EvoTips as per manufacturer's instructions. Briefly, the $\mathrm{C}_{18}$ EvoTips were activated using $20 \mu \mathrm{l}$ of $100 \%$ acetonitrile followed by equilibration with $20 \mu \mathrm{l}$ of $0.1 \%$ formic acid in water. Activation and equilibration was carried out at $700 \mathrm{x} \mathrm{g}$ for 1 minute. The sample was loaded at $500 \mathrm{x} \mathrm{g}$ for 5 minute followed by washing using $0.1 \%$ formic acid once. At last the tips were loaded with $100 \mu 1$ of $0.1 \%$ formic acid and processed for targeted analysis. 
medRxiv preprint doi: https://doi.org/10.1101/2020.08.05.20168948; this version posted August 6, 2020. The copyright holder for this preprint (which was not certified by peer review) is the author/funder, who has granted medRxiv a license to display the preprint in perpetuity.

All rights reserved. No reuse allowed without permission.

\section{Targeted Parallel Reaction Monitoring (PRM) analysis}

Parallel reaction monitoring (PRM) analysis was performed on an Exploris 480 mass spectrometer equipped with FAIMS Pro ion source (Thermo Scientific, Bremen, Germany) and interfaced with a preformed gradient LC system (EvoSep One, EvoSep Inc., Odense, Denmark). FAIMS Compensation voltages were optimized for peptides from nucleocapsid protein; AYNVTQAFGR and QQTVTLLPAADLDDFSK. Individual positive and negative swab samples were processed for antibody capture and trypsin digestion as described above. Peptides were eluted at a flow rate of $2 \mu \mathrm{l} /$ minute into a pre-formed gradient using the Evosep One LC system connected to the Exploris 480 mass spectrometer equipped with FAIMS Pro ion source. Peptide separation was carried out using a $4 \mathrm{~cm}$ analytical column (Dr. Maisch $\mathrm{C}_{18} \mathrm{AQ}, 1.9 \mu \mathrm{m}$, $150 \mu \mathrm{m} \times 4 \mathrm{~cm}$ ) with a 5.6 min gradient. Data acquisition parameters included MS1 scan from $560-100 \mathrm{~m} / \mathrm{z}$ at resolution of 60,000 followed by retention time scheduled PRM analysis of AYNVTQAFGR and QQTVTLLPAADLDDFSK peptides and corresponding double SIL heavy peptides. The PRM parameters included: Orbitrap resolution of 60,000, AGC target value of $5 \mathrm{x}$ $10^{4}$, injection time of $118 \mathrm{~ms}$, isolation window of $\mathrm{m} / z, 1$ and HCD normalized collision energy of 27. Table 1 shows targeted inclusion list with retention time scheduled PRM scans for light and heavy versions of AYNVTQAFGR and QQTVTLLPAADLDDFSK with corresponding FAIMS compensation voltages (CV).

\section{Mass spectrometry data analysis of untargeted LC-MS/MS data}

The raw mass spectrometry data were searched using Andromeda in MaxQuant software suite (version 1.6.7.0) (30) against a combined protein database of SARS-CoV-2 proteins, SARS-CoV proteins, common coronaviruses (OC43, HKU1, NL63 and L229E) and UniProt human protein database, African green monkey (Chlorocebus aethiops) database (in case of irradiated virus MS data) including common MS contaminants. The search parameters included a maximum of two missed cleavages; carbamidomethylation at cysteine as a fixed modification for samples that were reduced and alkylated; N-terminal acetylation and oxidation at methionine as variable modifications. Precursor tolerance was set to $10 \mathrm{ppm}$ and MS/MS tolerance to $\pm 0.02 \mathrm{Da}$. False discovery rate was set to $1 \%$ at the peptide-spectrum matches (PSMs), peptide and protein levels.

\section{Data analysis of targeted LC-MS/MS data}

The PRM data were processed using the Skyline software package (31). PRM data were assessed for (i) peak symmetry and baseline; (ii) consistency of retention times and (iii) retention time consistency across transitions of the same analyte. In addition, peak integration of extracted ion chromatogram of all plausible fragments of light and heavy precursor was adjusted manually to avoid potential interferences. The fragment ion intensities were exported from skyline and (natural) log transformed. A supervised machine learning method was used to select the optimal fragments and determine their weights for maximizing the performance of the targeted mass spectrometry assay. All computations were performed in R (version 4.0.1). For this, we utilized an ensemble-based machine learning approach encoded in the Super Learner as described previously. This method was configured to use a generalized linear model via penalized maximum likelihood (glmNET), generalized linear model (glm) and random forest model; all 
medRxiv preprint doi: https://doi.org/10.1101/2020.08.05.20168948; this version posted August 6, 2020. The copyright holder for this preprint (which was not certified by peer review) is the author/funder, who has granted medRxiv a license to display the preprint in perpetuity.

All rights reserved. No reuse allowed without permission.

configured to use binomial distribution. A 10-fold cross-validation with a goal to maximize the AUC was instituted during the learning process. An optimal weighted average of the different trained models was computed and considered as final model for an independent validation. 


\section{FIGURES}

Figure 1. Overview of the annotated genome (A) and domain organization of key structural components: nucleocapsid and spike proteins (B) of SARS-CoV-2 along with sequence coverage obtained by peptides identified by mass spectrometry in this study. Overview of proteins and peptides from SARS-CoV-2 identified in discovery studies by bottom-up mass spectrometry (C). Red boxes represent peptides that were detected while unfilled boxes represent peptides that were not detected in the indicated samples.

Figure 2. Experimental annotated MS/MS spectra of peptides identified from the nucleocapsid protein of SARS-CoV-2 positive nasopharyngeal swab specimens are shown. GQGVPINTNSSPDDQIGYYR (A), NPANNAAIVLQLPQGTTLPK (B), AYNVTQAFGR (C) and QQTVTLLPAADLDDFSK (D). Sequence alignment of the four most abundant peptides that were chosen for development of PRM assays (E) - GQGVPINTNSSPDDQIGYYR (69-88), NPANNAAIVLQLPQGTTLPK (150-169), AYNVTQAFGR (267-276) and QQTVTLLPAADLDDFSK (389-405) derived from SARS-CoV-2 nucleocapsid protein across related coronaviruses (SARS-CoV, MERS and common human coronaviruses: L229E, NL63, HKU1 and OC43). Amino acid mismatches are indicated in red while tryptic cleavage sites $(\mathrm{R} / \mathrm{K})$ are underlined.

Figure 3. A schematic of FAIMS-PRM targeted assay for the detection of diagnosis of SARSCoV-2. Heat-inactivated nasopharyngeal swab samples were immunopurified with antinucleocapsid antibody coated on MSIA D.A.R.T.s ${ }^{\mathrm{TM}}$ tips using Versette automated liquid handler, in-solution trypsin digested. Targeted LC-MS/MS analysis was carried out on Exploris 480 mass spectrometer interfaced with rapid chromatography system and a FAIMS Pro interface.

Figure 4. Box plot showing predicted probability for training dataset (A) and validation dataset (B). Population distribution of nasopharyngeal swab samples tested by RT-PCR assay at Mayo Clinic (C), Distribution of clinical samples tested using targeted FAIMS-PRM method in this study (D), Targeted FAIMS-PRM fragment ion intensity against $\mathrm{Ct}$ values of nasopharyngeal swab samples for AYNVTQAFGR (E) and QQTVTLLPAADLDDFSK (F) peptides.

\section{SUPPLEMENTARY FIGURES}

Figure S1. Sequence alignment of SARS-CoV-2 nucleocapsid protein against related coronaviruses: SARS-CoV, MERS and common human coronaviruses (L229E, NL63, HKU1 and OC43). Sequence in red indicates the regions that were identified by mass spectrometry while the underlined sequences were selected for targeted PRM analysis.

Figure S2. Extracted ion chromatogram (EIC) for the top three fragments (m/z 678.36, 778.43, 892.47) of AYNVTQAFGR peptide $(\mathrm{m} / \mathrm{z}$ 563.78) in nasopharyngeal swab IP samples with $\mathrm{Ct}$ value of 20 (A) and Ct value of 30 (B). Top panels in both (A) and (B) are with FAIMS while bottom panels are without FAIMS.

\section{TABLES:}


Table 1: Peptides from nucleocapsid protein used for targeted FAIMS-PRM analysis for the detection of SARS-CoV-2 in nasopharyngeal swab samples. The table includes peptide sequence, precursor $m / z$, precursor charge, retention time (start and end) in minutes and optimized compensation voltage $(\mathrm{CV})$.

\section{SUPPLEMENTARY TABLES}

Table S1: List of all proteins and peptide identified by mass spectrometry across various sample types analyzed in this study.

Table S2: Fragment ion intensities of direct digest and immunopurified samples analyzed by targeted PRM experiments.

Table S3: List of all antibodies used for evaluation for enrichment and detection of nucleocapsid and/or spike glycoprotein from SARS-CoV-2

Table S4: Fragment ion intensities of nasopharyngeal swab IP samples analyzed by FAIMS and noFAIMS targeted PRM method.

Table S5: Fragment ion intensities of nasopharyngeal swab IP samples analyzed used for machine learning training and validation. 
medRxiv preprint doi: https://doi.org/10.1101/2020.08.05.20168948; this version posted August 6, 2020. The copyright holder for this preprint (which was not certified by peer review) is the author/funder, who has granted medRxiv a license to display the preprint in perpetuity.

All rights reserved. No reuse allowed without permission.

Table 1

\begin{tabular}{|l|c|c|c|c|c|}
\hline \multicolumn{1}{|c|}{ Peptide } & $\mathbf{m} / \mathbf{z}$ & Charge State & $\begin{array}{c}\text { Start } \\
(\mathbf{m i n}\end{array}$ & $\begin{array}{c}\text { End } \\
(\mathbf{m i n})\end{array}$ & $\begin{array}{c}\text { FAIMS Pro } \\
\text { CV }\end{array}$ \\
\hline AYNVTQAFGR & 563.7856 & 2 & 2.5 & 3.5 & -40 \\
\hline AYNVTQA(+3Da)FGR(+10Da) (Heavy IS) & 570.2948 & 2 & 2.5 & 3.5 & -40 \\
\hline QQTVTLLPAADLDDFSK & 931.4807 & 2 & 3.5 & 5.3 & -30 \\
\hline QQTVTLLPAADL(+7Da)DDFSK(+8Da) (Heavy IS) & 938.9964 & 2 & 3.5 & 5.3 & -30 \\
\hline
\end{tabular}




\section{REFERENCES:}

1. Cui J, Li F, Shi ZL. Origin and evolution of pathogenic coronaviruses. Nat Rev Microbiol. 2019;17(3):181-92.

2. Zhong NS, Zheng BJ, Li YM, Poon, Xie ZH, Chan KH, et al. Epidemiology and cause of severe acute respiratory syndrome (SARS) in Guangdong, People's Republic of China, in February, 2003. Lancet. 2003;362(9393):1353-8.

3. Zaki AM, van Boheemen S, Bestebroer TM, Osterhaus AD, Fouchier RA. Isolation of a novel coronavirus from a man with pneumonia in Saudi Arabia. N Engl J Med. 2012;367(19):1814-20.

4. Wang C, Horby PW, Hayden FG, Gao GF. A novel coronavirus outbreak of global health concern. Lancet. 2020;395(10223):470-3.

5. Li Q, Guan X, Wu P, Wang X, Zhou L, Tong Y, et al. Early Transmission Dynamics in Wuhan, China, of Novel Coronavirus-Infected Pneumonia. N Engl J Med. 2020;382(13):1199207.

6. Madjid M, Safavi-Naeini P, Solomon SD, Vardeny O. Potential Effects of Coronaviruses on the Cardiovascular System: A Review. JAMA Cardiol. 2020.

7. Yang X, Yu Y, Xu J, Shu H, Xia J, Liu H, et al. Clinical course and outcomes of critically ill patients with SARS-CoV-2 pneumonia in Wuhan, China: a single-centered, retrospective, observational study. Lancet Respir Med. 2020.

8. Cheng Y, Luo R, Wang K, Zhang M, Wang Z, Dong L, et al. Kidney disease is associated with in-hospital death of patients with COVID-19. Kidney Int. 2020;97(5):829-38.

9. Wong SH, Lui RN, Sung JJ. Covid-19 and the digestive system. J Gastroenterol Hepatol. 2020.

10. Lin L, Jiang X, Zhang Z, Huang S, Zhang Z, Fang Z, et al. Gastrointestinal symptoms of 95 cases with SARS-CoV-2 infection. Gut. 2020.

11. Li LY, Wu W, Chen S, Gu JW, Li XL, Song HJ, et al. Digestive system involvement of novel coronavirus infection: prevention and control infection from a gastroenterology perspective. J Dig Dis. 2020.

12. Zhang C, Shi L, Wang FS. Liver injury in COVID-19: management and challenges. Lancet Gastroenterol Hepatol. 2020;5(5):428-30.

13. Huang C, Wang Y, Li X, Ren L, Zhao J, Hu Y, et al. Clinical features of patients infected with 2019 novel coronavirus in Wuhan, China. Lancet. 2020;395(10223):497-506.

14. Musa S. Hepatic and gastrointestinal involvement in coronavirus disease 2019 (COVID19): What do we know till now? Arab J Gastroenterol. 2020;21(1):3-8.

15. Li YC, Bai WZ, Hashikawa T. The neuroinvasive potential of SARS-CoV2 may play a role in the respiratory failure of COVID-19 patients. J Med Virol. 2020.

16. Udugama B, Kadhiresan P, Kozlowski HN, Malekjahani A, Osborne M, Li VYC, et al. Diagnosing COVID-19: The Disease and Tools for Detection. ACS Nano. 2020;14(4):3822-35.

17. Zou L, Ruan F, Huang M, Liang L, Huang H, Hong Z, et al. SARS-CoV-2 Viral Load in Upper Respiratory Specimens of Infected Patients. N Engl J Med. 2020;382(12):1177-9.

18. Hong KH, Lee SW, Kim TS, Huh HJ, Lee J, Kim SY, et al. Guidelines for Laboratory Diagnosis of Coronavirus Disease 2019 (COVID-19) in Korea. Ann Lab Med. 2020;40(5):35160 . 
medRxiv preprint doi: https://doi.org/10.1101/2020.08.05.20168948; this version posted August 6, 2020. The copyright holder for this preprint (which was not certified by peer review) is the author/funder, who has granted medRxiv a license to display the preprint in perpetuity.

All rights reserved. No reuse allowed without permission.

19. Kammila S, Das D, Bhatnagar PK, Sunwoo HH, Zayas-Zamora G, King M, et al. A rapid point of care immunoswab assay for SARS-CoV detection. J Virol Methods. 2008;152(1-2):7784.

20. Che XY, Hao W, Wang Y, Di B, Yin K, Xu YC, et al. Nucleocapsid protein as early diagnostic marker for SARS. Emerg Infect Dis. 2004;10(11):1947-9.

21. Cho SJ, Woo HM, Kim KS, Oh JW, Jeong YJ. Novel system for detecting SARS coronavirus nucleocapsid protein using an ssDNA aptamer. J Biosci Bioeng. 2011;112(6):53540 .

22. Lin Y, Shen X, Yang RF, Li YX, Ji YY, He YY, et al. Identification of an epitope of SARS-coronavirus nucleocapsid protein. Cell Res. 2003;13(3):141-5.

23. Chang CK, Hou MH, Chang CF, Hsiao CD, Huang TH. The SARS coronavirus nucleocapsid protein--forms and functions. Antiviral Res. 2014;103:39-50.

24. Bar-On YM, Flamholz A, Phillips R, Milo R. SARS-CoV-2 (COVID-19) by the numbers. Elife. 2020;9.

25. Bollinger JG, Stergachis AB, Johnson RS, Egertson JD, MacCoss MJ. Selecting Optimal Peptides for Targeted Proteomic Experiments in Human Plasma Using In Vitro Synthesized Proteins as Analytical Standards. Methods Mol Biol. 2016;1410:207-21.

26. Swearingen KE, Moritz RL. High-field asymmetric waveform ion mobility spectrometry for mass spectrometry-based proteomics. Expert Rev Proteomics. 2012;9(5):505-17.

27. Bekker-Jensen DB, Martinez-Val A, Steigerwald S, Ruther P, Fort KL, Arrey TN, et al. A Compact Quadrupole-Orbitrap Mass Spectrometer with FAIMS Interface Improves Proteome Coverage in Short LC Gradients. Mol Cell Proteomics. 2020;19(4):716-29.

28. van der Laan MJ, Polley EC, Hubbard AE. Super learner. Stat Appl Genet Mol Biol. 2007;6:Article25.

29. Basu A, Zinger T, Inglima K, Woo KM, Atie O, Yurasits L, et al. Performance of Abbott ID NOW COVID-19 rapid nucleic acid amplification test in nasopharyngeal swabs transported in viral media and dry nasal swabs, in a New York City academic institution. J Clin Microbiol. 2020 .

30. Cox J, Mann M. MaxQuant enables high peptide identification rates, individualized p.p.b.-range mass accuracies and proteome-wide protein quantification. Nat Biotechnol. 2008;26(12):1367-72.

31. MacLean B, Tomazela DM, Shulman N, Chambers M, Finney GL, Frewen B, et al. Skyline: an open source document editor for creating and analyzing targeted proteomics experiments. Bioinformatics. 2010;26(7):966-8. 


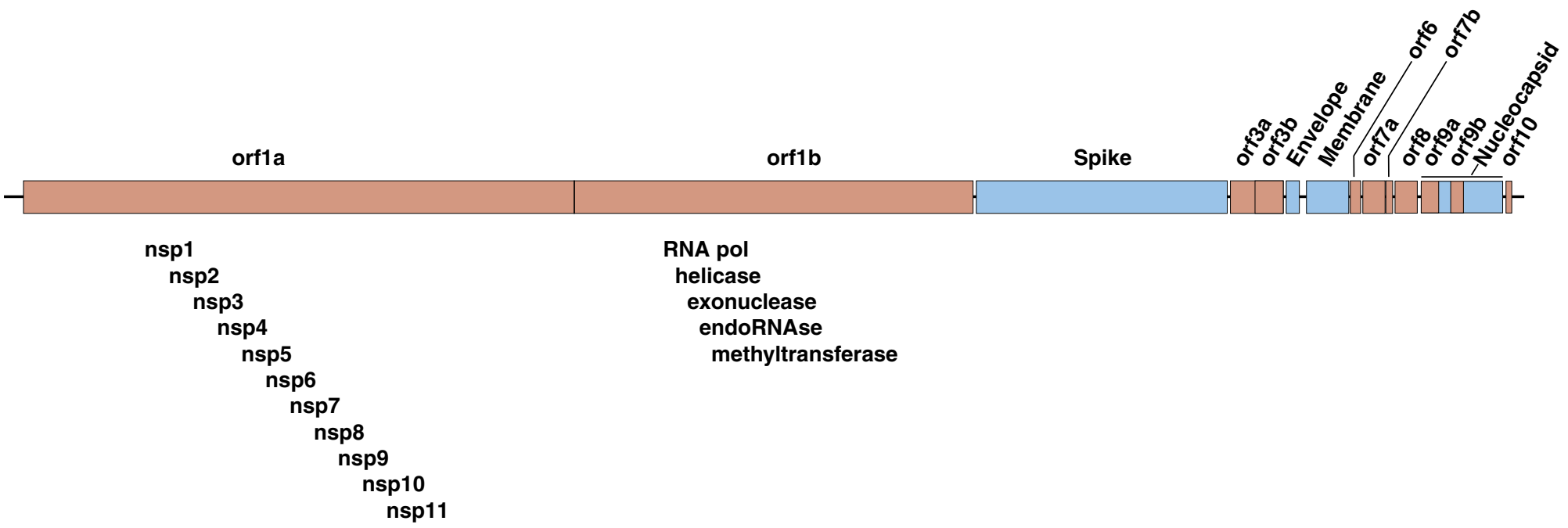

B

\section{Nucleocapsid}

\begin{tabular}{|c|c|c|c|c|}
\hline IDR & RBD & SR & NLS & IDR \\
\hline
\end{tabular}

\section{Spike}

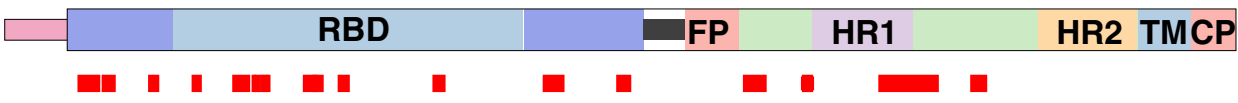

Identified peptides

Purified SARS-CoV-2 virus

Recombinant nucleocapsid Pooled swab

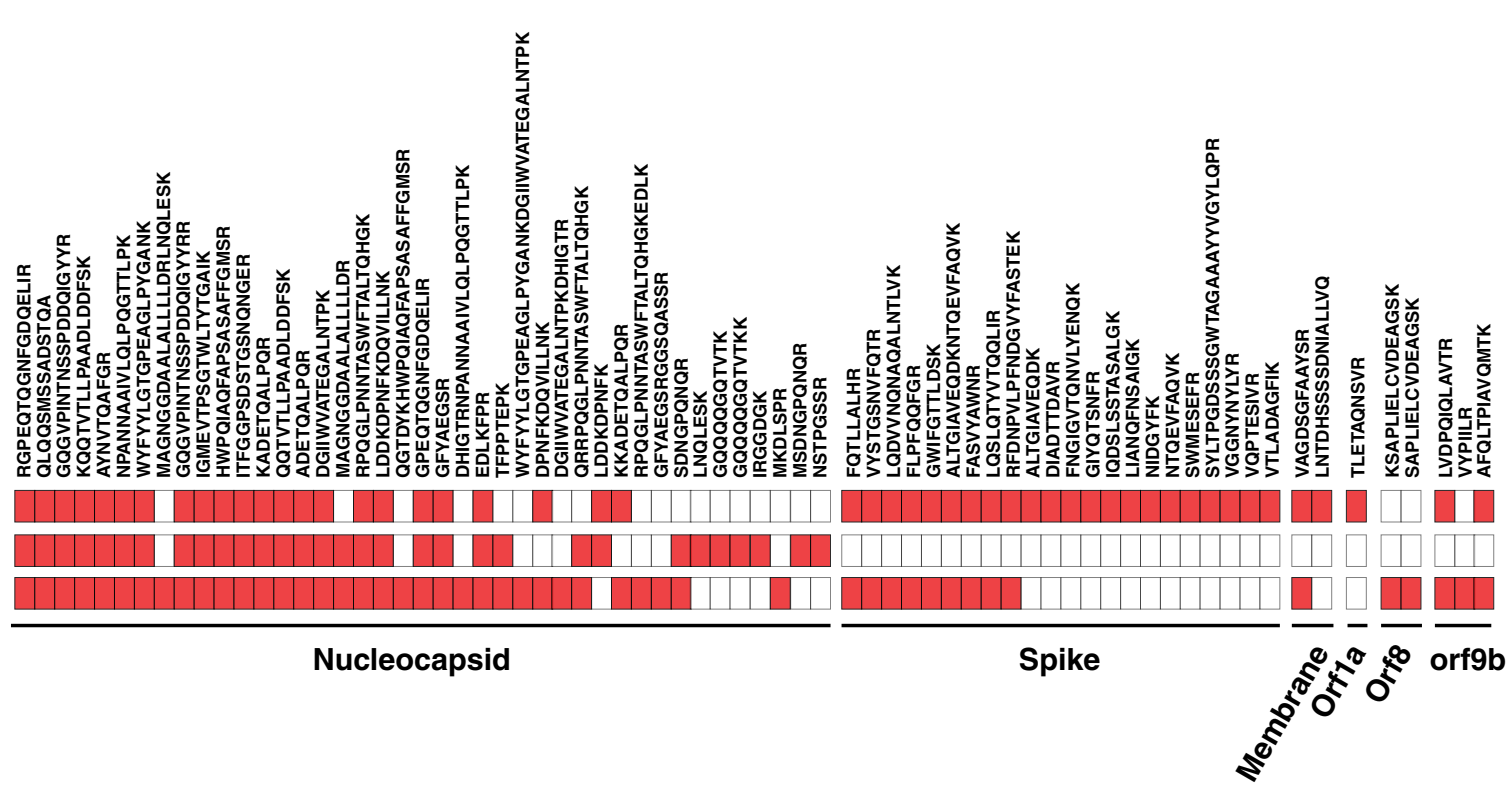




\section{Figure 2}

A medRxiv preprint doi: https://doi.org/10.1101/2020.08.05.20168948; 3 s version posted August 6, 2020. The copyright holder for this preprint

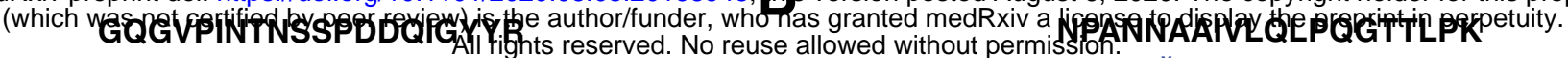
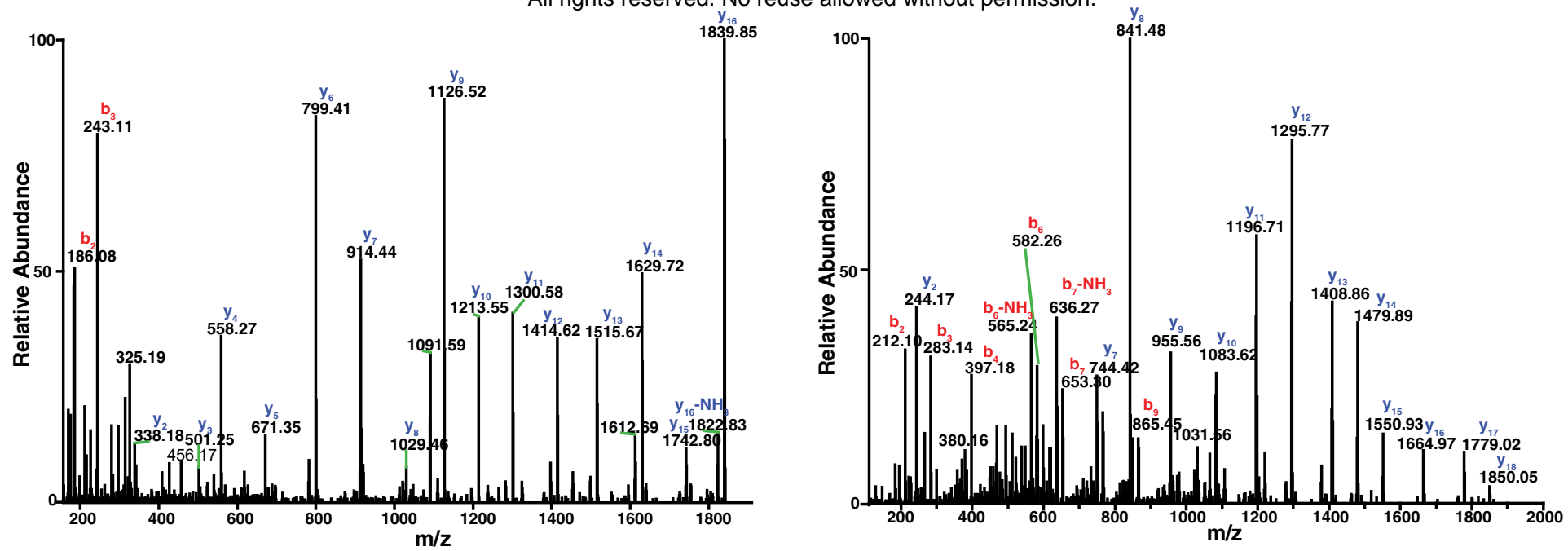

C

AYNVTQAFGR

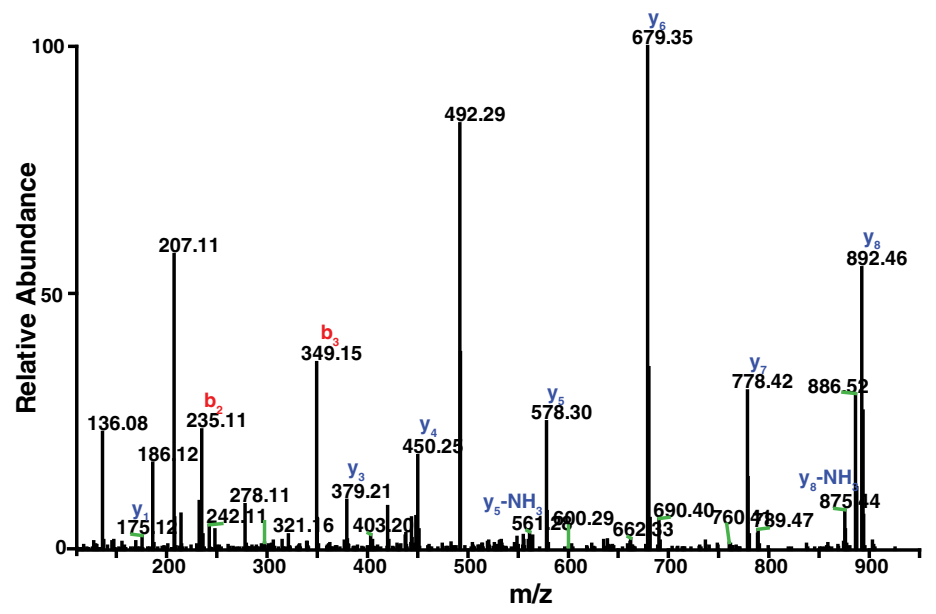

D

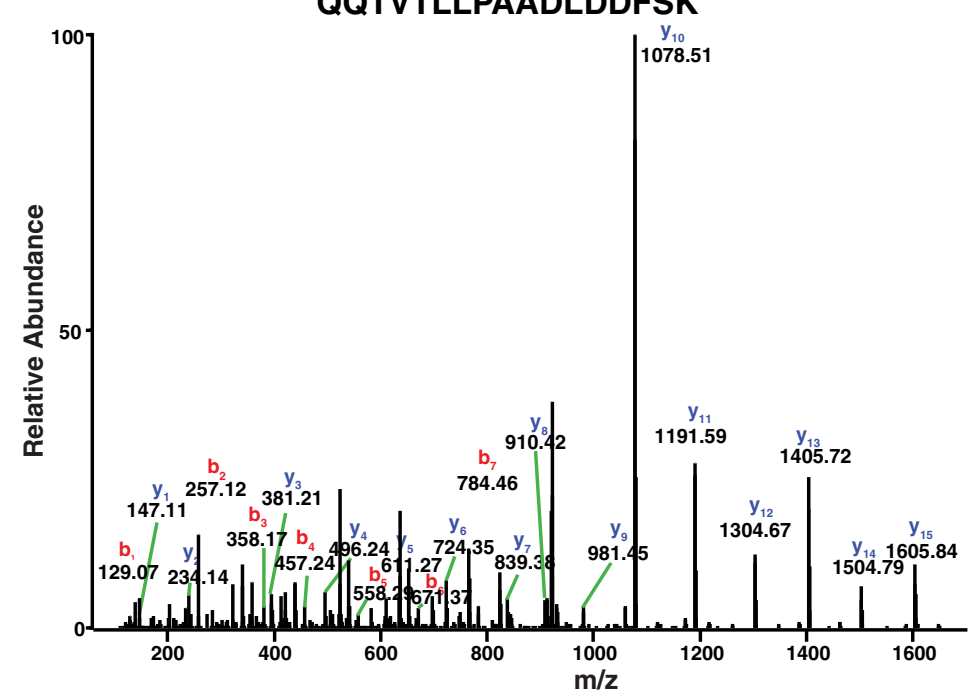

E

GQGVPINTNSSPDDQIGYYR GQGVPINTNSGPDDQIGYYR GQGVPLNANSTPAQNAGYWR RNLVPINKKD-KNKLIGYWN RNLVPIGKGNGQGVPIAF'GVP $\bar{P}$ SEAKGYWY GQGVPIAPGVPATEĀKGYWY
NPANNAAIVLQLPQGTTLPK NPNNNAATVLQLPQGTTLPK NPNYNKWLELLEONIDAYKT RKNSE PEIPHFNQKLPNGVTT KRNQKPLEPKFSIĀLPPELS DPTTQEAIPTRFPPGTILPQ DPSSDEAIPTRFPPGTVLPQ
SARS-CoV-2

SARS-CoV

MERS

L229E

NL63

HKU1

OC43
Common

Human

Coronaviruses

\begin{abstract}
AYNVTQAFGR QYNVTQAFGR SFNMVQAFGL TSNVTQCFGP EENVIQCFGP HCNVQQCFGK QCTVQQCFGK్
\end{abstract}

QQTVTLLPAADLDDFSK QPTVTLLPAADMDDFSR RPSVQPGPMIDVNTD-TSPATAEPVRDEVSIET ASIPESKPLADDDSAII SLNLSAGTQHISNDFTP NISVAVPKSRVQQNKSR
SARS-CoV-2 SARS-CoV MERS L229E NL63 HKU1 OC43
Common

Human Coronaviruses 


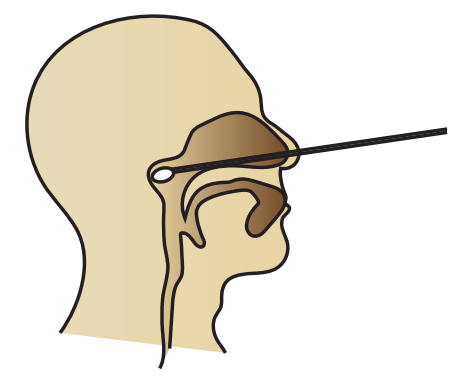

Nasopharyngeal swab sample collection

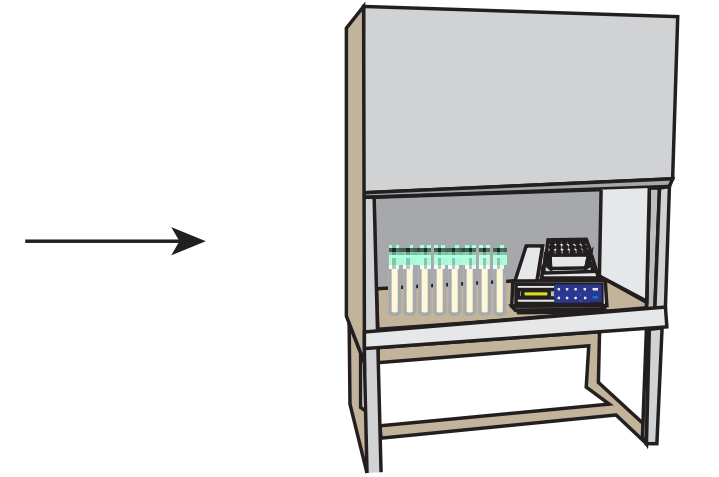

Heat inactivation

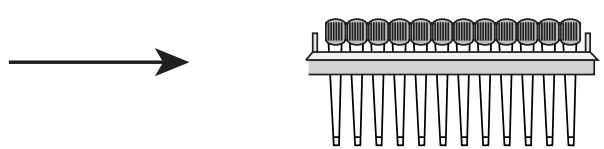

Antibody Biotinylation and coupling to MSIA tips
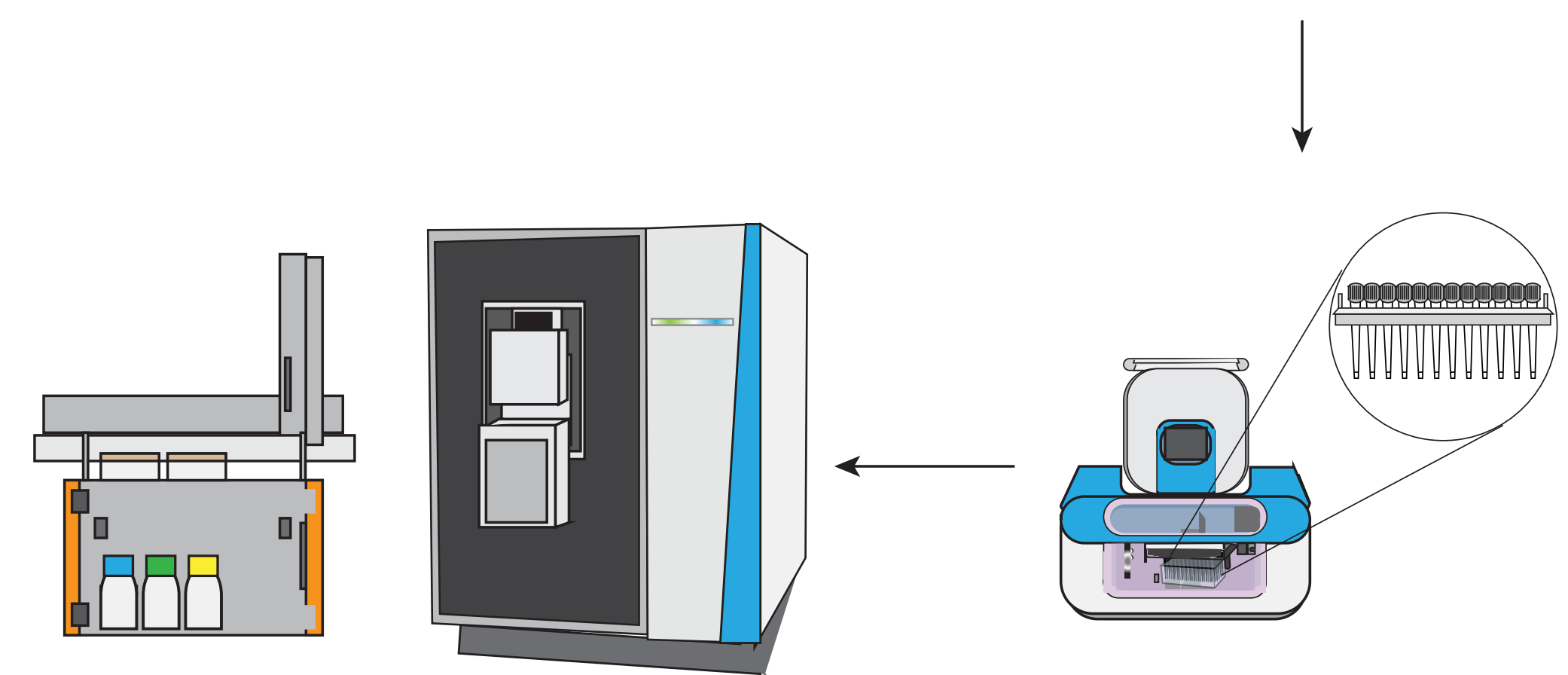

Targeted PRM analysis using preformed fast gradient LC and high resolution Orbitrap mass spectrometer

Automated Mass-Spec Immunoassay (MSIA)-based enrichment of antigen and in-solution trypsin digestion 
medRxiv preprint doi: https://doi.org/10.1101/2020.08.05.20168948; this version posted August 6, 2020. The copyright holder for this preprint

(which was not certified by peer review) is the author/funder, who has granted medRxiv a license to display the preprint in perpetuity.

A

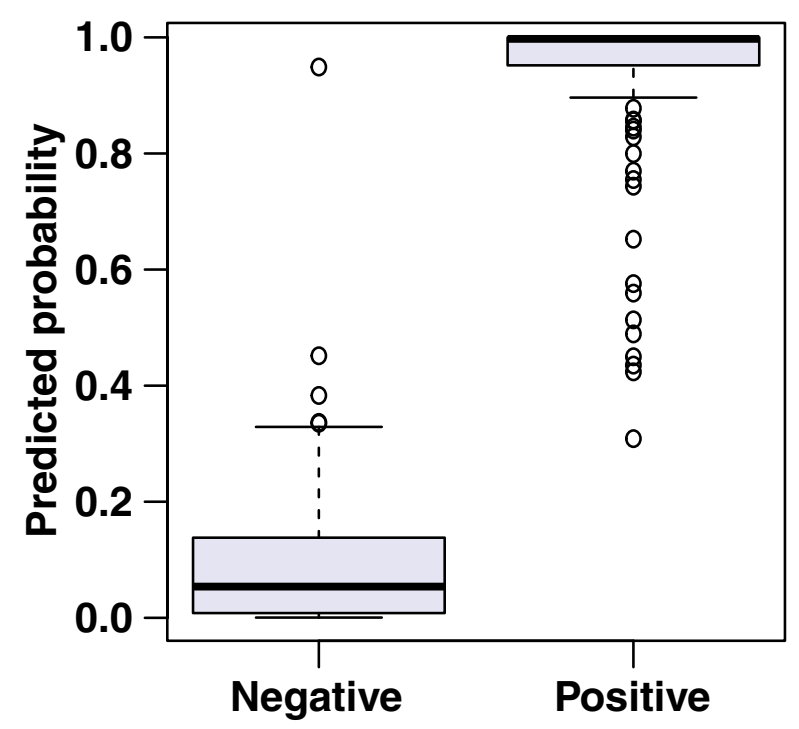

C

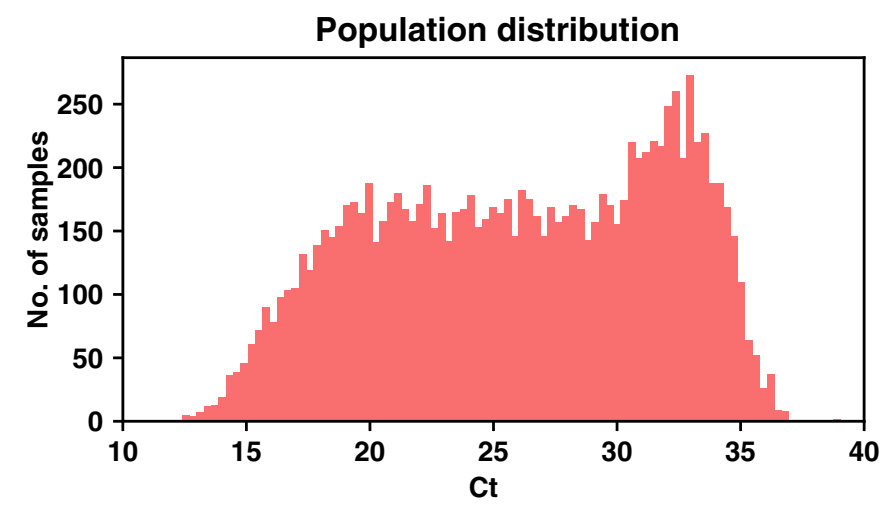

$\mathbf{E}$

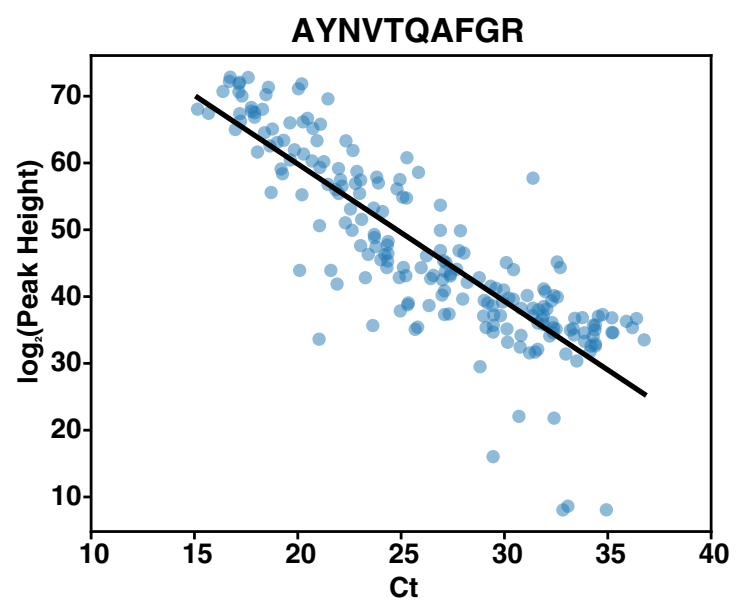

B

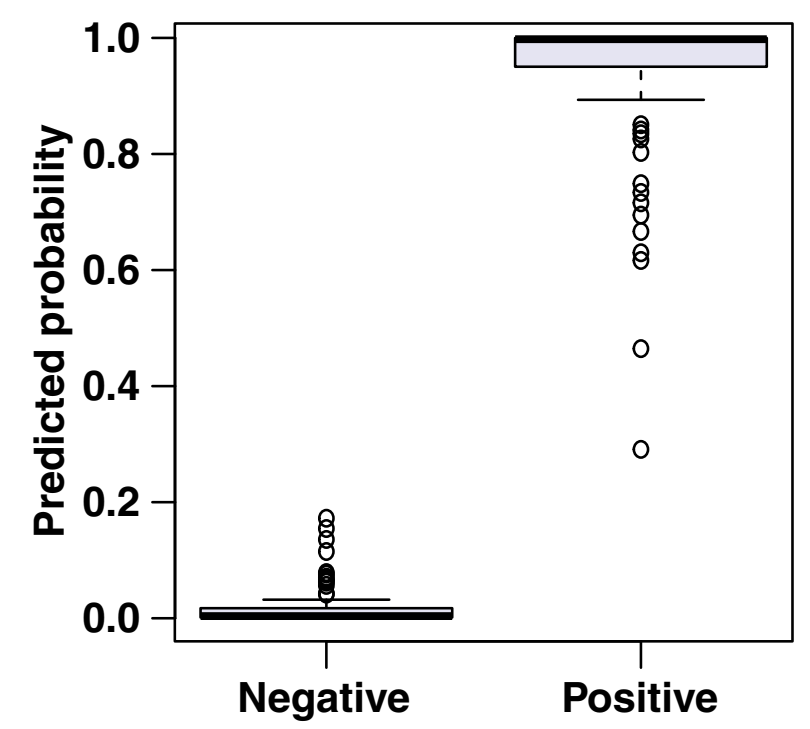

D

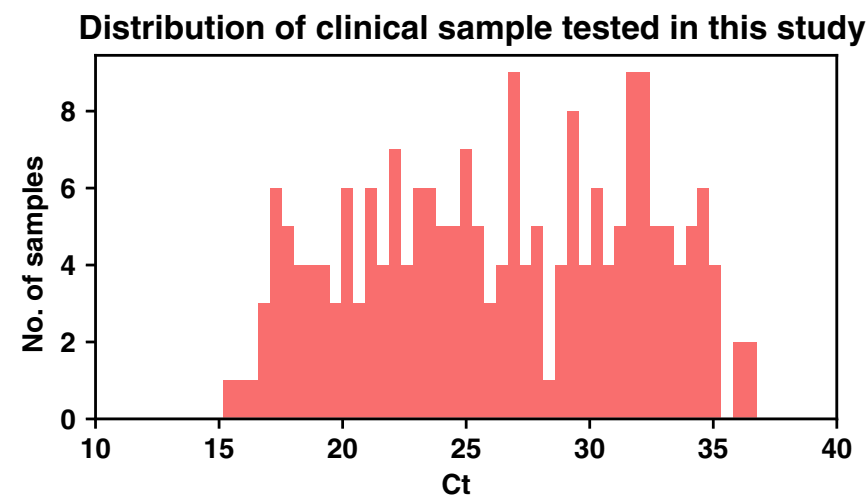

F

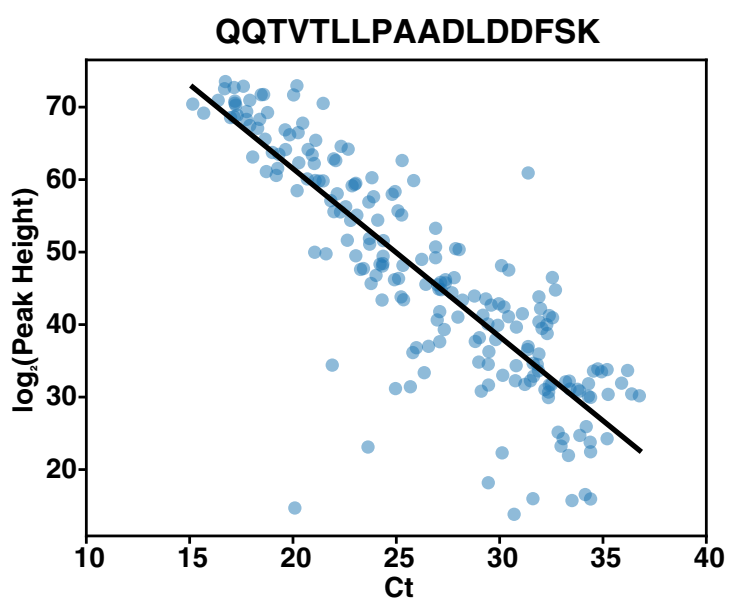




\section{Figure S1}

MSD-NGPQ-NQ-------RNAPRITFGGPSDSTGSNQNGERSGARSK-------QRRPQGLPNNTASWFTALTQHGK-EDLKFPRGQGVPINTNSSPDD MSD-NGPQSNQ-------RSAPRITFGGPTDSTDNNQNGGRNGARPK-------QRRPQGLPNNTASWFTALTQHGK-EELRFPRGQGVPINTNSGPDD ------MASP--------AAPRAVSFADNNDITNTN----LSRGRGR--------NPKPRAAPNNTVSWYTGLTQHGK-VPLTFPPGQGVPLNANSTPAQ -----------------MATVKWADASEPQ--------RGRQ--------------GRIPYSLYSPLLVDS-EQPWKVIPRNLVPINKKD-KNK

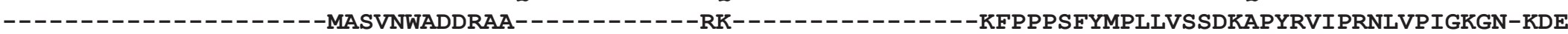
MSYTPGHYAGSRSSSGNRSGILKKTSWADQSERNYQTF----NRGRKTQPKFTVST--QPQGNTI PHYSWFSGITQFQKGRDFKFSDGQGVPIAFGVPPSE MSFTPGKQSSSRASSGNRSGNG-ILKWADQSDQFRNVQ----TRGRRAQPKQTATSQQPSGGNVVPYYSWFSGITQFQKGKEFEFVEGQGVPIAPGVPATE

QIGYYRRATRR-IRGGDGKMKDLSPRWYFYYLGTGPEAGLPYGANKDGI IWVATEGALNTPKDHIGTRNPANNAAIVLQLPQGTTLPKGFYAEGSRGGSQA QIGYYRRATRR-VRGGDGKMKELSPRWYFYYLGTGPEASLPYGANKEGIVWVATEGALNTPKDHIGTRNPNNNAATVLQLPQGTTLPKGFYAEGSRGGSQA NAGYWRRODRK-INTGNG-IKOLAPRWYFYYTGTGPEAALPFRAVKDGIVWVHEDGATDAPS-TFGTRNPNNDSAIVTQFAPGTKLPKNFHIEGTGGNSOS LIGYWNVQKR--FRTRKGKRVDLSPKLHFYYLGTGPHKDAKFRERVEGVVWVAVDGAKTEPT-GYGVRRKNSEPEIPH-F--NQKLPNGVTVVEEPDSRAQIGYWNVQER--WRMRRGQRVDLPPKVHFYYLGTGPHKDLKFRQRSDGVVWVAKEGAKTVNT-SLGNRKRNQKPLEPK-F--SIALPPELSVVEFEDRSNN AKGYWYRHSRRSFKTADGQQKQLLPRWYFYYLGTGPYANASYGESLEGVFWVANHQADTSTPSDVSSRDPTTQEAIPTRFPPGTILPQGYYVEGSGRSASN AKGYWYRHNRRSFKTADGNQRQLLPRWYFYYLGTGPHAKDQYGTDIDGVYWVASNQADVNTPADIVDRDPSSDEAIPTRFPPGTVLPQGYYIEGSGRSAPN

$$
\text { * }
$$

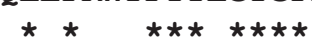

* $\star \star$

*
* $\star \star$

SSRSS--SRSRNSSRNSTPGS---SRG-TSPARMA---GNGGDAALALLLLDRLNQLESK-MSGKG--Q-QQQGQTVT------------KKSAA----EA SSRSS--SRSRGNSRNSTPGS---SRG-NSPARMA---SGGGETALALLLLDRLNQLESK-VSGKG--Q-QQQGQTVT------------KKSAA----EA SSRAS--SVSRNSSRSSSQGS---RSG-NSTRGTSPGPSGIGAVGGDLLYLDLLNRLQAL-ESGKV--K-QSQPKVIT------------KKDAA----AA ----PSRSOSRSOSRGRGESKPOSRNPSSDRNHNS-ODDIMKAVAAALKSLGFDKPOEKDKKSAKTGTPKPSRNOSPASSOTSAKSLARSOSSETKEOKHE SSRASSRSSTRNNSRDSSRSTSRQQSRTRSDSNQS-SSDLVAAVTLALKNLGFDNQSKSPSSS---GTSTPKKPNKPL-------------SQPRADKPSQ -SR----PGSRSOSRGPNNRS---ISRSNSNFRHS----------DSIVKPDMADEIANL-VIAKLGKD-S-KPOOVT------- ----KONAKEIRHKI -SR----STSRTSSRASSAGS---RSRANSGNRTP----------TSGVTPDMADQIASL-VLAKLGKD-ATKPQQVT------------KHTAKEVRQKI * $\star *$

SKKPRQKRTATKA--YNVTQAFGRRGPEQTQGNFGDQELIRQGTDYKHWPQIAQFAPSASAFFGMSRIGMEVTP-----------SGTWLTYTGAIKLDDK SKKPRQKRTATKQ--YNVTQAFGRRGPEQTQGNFGDQDLIRQGTDYKHWPQIAQFAPSASAFFGMSRIGMEVTP-----------SGTWLTYHGAIKLDDK KNKMRHKRTSTKS--FNMVQAFGLRGPGDLQGNFGDLQLNKLGTEDPRWPQIAELAPTASAFMGMSQFKLTHQN-----NDDHGNPVYFLRYSGAIKLDPK MQKPRWKRQPNDDVTSNVTQCFGPRDLDH---NFGSAGVVANGVKAKGYPQFAELVPSTAAMLFDSHIVSKESG-----------NTVVLTFTTRVTVPKD LKKPRWKRVPTRE--ENVIQCFGPRDFNH---NMGDSDLVQNGVDAKGFPQLAELI PNQAALFFDSEVSTDEVG-----------DNVQITYTYKMLVAKD LTKPRQKRTPNKH--CNVQQCFGKRGPSQ---NFGNAEMLKLGTNDPQFPILAELAPTPGAFFFGSKLDLVKRD---SEADSPVKDVFELHYSGSIRFDST LNKPRQKRSPNKQ--CTVQQCFGKRGPNQ---NFGGGEMLKLGTSDPQFPILAELAPTAGAFFFGSRLELAKVQNLSGNPDEPQKDVYELRYNGAIRFDST

$$
\text { * * ** }
$$

DPNFKDQVILLNKHIDAYKTFPPTEPKKDKKKKADET--QALPQ--------R-QKKQQTV-------TLLPAADLDDFSKQLQQSMSSADSTQA--DPQFKDNVILLNKHIDAYKTFPPTEPKKDKKKKTDEA--QPLPQ--------R-QKKQPTV-------TLLPAADMDDFSRQLQNSMSGASADSTQANPNYNKWLELLEQNIDAYKTFPKKEKKQKAPKEESTDQMSEPPKEHRVQGTQR-TRTRPSV-------QPGPMIDVNTD-------------------

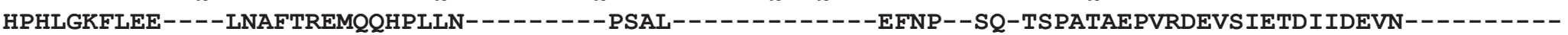
NKNLPKFIEQ----ISAFTKPSS IKEMQS---------QSSH------------VAQNTVLN-ASI PESKPLADDDSAI IEIVNEVLH--------LPGFETIMKVLEENLNAYVNSNQN---------TDSDSLSSKPQRKRGVKQLPEQFDSLNLSA----GTQHISNDFTPEDHSLLATLDDPYVEDSVALSGFETIMKVLNENLNAYQQQDG-----------MMNMSPKPQRQRGHKNGQGENDNISVAVPKSRVQQNKSRELTAEDISLLKKMDEPYTEDTSEI
SARS-CoV-2

SARS-CoV

MERS

L229E

NL63

HKU1

OC43

Common

Human Coronaviruses

SARS-CoV-2

SARS-CoV

MERS

L229E

NL63

HKU1

Common

Human

OC43

Coronaviruses

\section{SARS-CoV-2}

SARS-COV

MERS

L229E

NL63

HKU1

Common

Human

OC43

Coronaviruses

\section{SARS-CoV-2}

SARS-CoV

MERS

L229E

NL63

HKU1

Common

OC43

Human Coronaviruses

SARS-CoV-2

SARS-COV

MERS

L229E

NL63

HKU1

Common

OC43 
medRxiv preprint doi: https://doi.org/10.1101/2020.08.05.20168948; this version posted August 6, 2020. The copyright holder for this preprint (which was not certified by peer review) is the author/funder, who has granted medRxiv a license to display the preprint in perpetuity.

All rights reserved. No reuse allowed without permission.

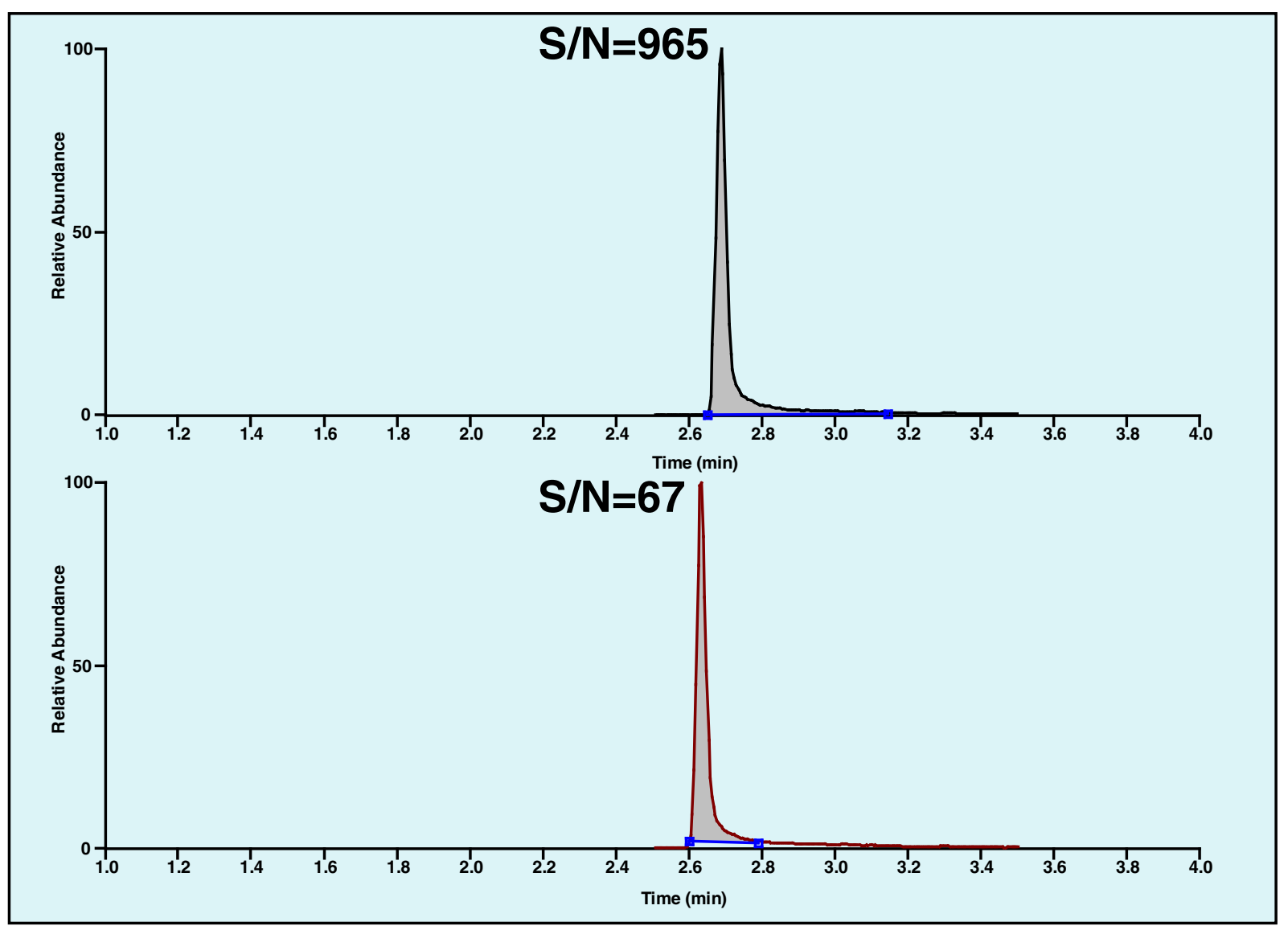

B
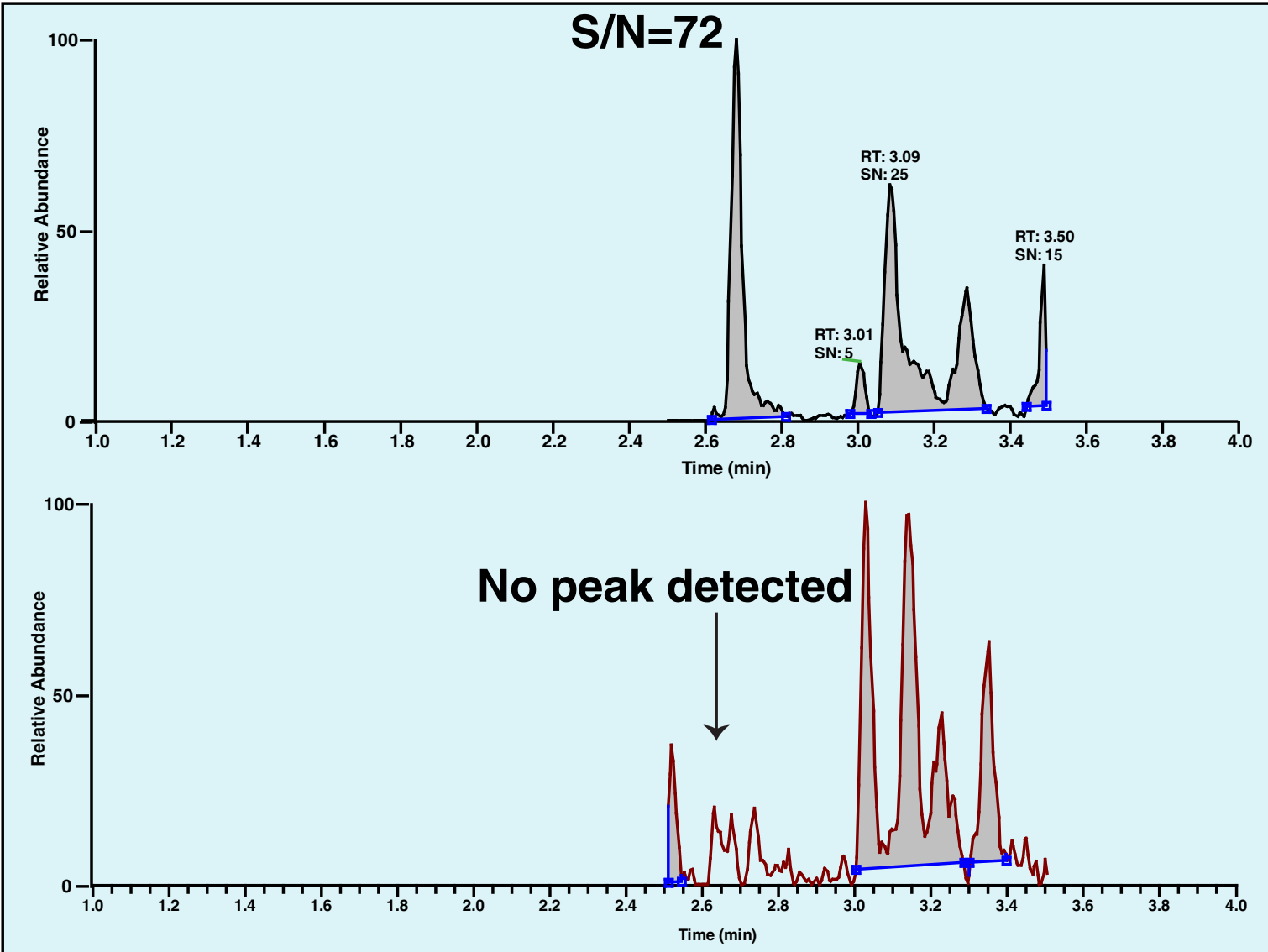